\title{
Real Time Distributed Systems Modeling and Control: Application to Photovoltaic Fuel Cell Electrolyser System
}

\author{
Soukaina Boudoudouh* and Mohamed Maâroufi \\ ${ }^{I}$ Department of Electrical Engineering, Mohammadia School of engineers (EMI), Mohammed V University, Rabat, Morocco
}

Received 21 December 2016; Accepted 18 February 2017

\begin{abstract}
Old grids which are more dependent on centralized power stations had shown incapacity in term of integrating large amounts of geometrically dispersed consumers and energy resources such as renewable energy resources (RES), that require a scheduled control between the variable demand and intermittent sources. The bi-directional electricity networks that can greet and control more than individual grid or element, is a complex system that requires a real need for intelligent distributed energy management (DEM) to address challenges of integration of a huge number of types of energy resources with different sizes. This paper proposes a real-time distributed systems modeling and control such as photovoltaic (PV)-fuel cell (FC)-Electrolyser system by multi-agent system (MAS). The main consideration is to show a new approach, able to communicate multi-threaded environment like MAS inside S-function of Simulink. Contrarily to the studies available in the literature, this approach allows agents to decide and negotiate to achieve the energy management objectives, while all calculations required to control dynamic system with continuous functions are made in Simulink.
\end{abstract}

Keywords: Real time distributed systems modeling and control, Photovoltaic (PV), Fuel cell (FC), electrolyser, Decision making, Multi agent system (MAS), MacsimJX, Jade, Matlab Simulink, Co-simulation

\section{Introduction}

The DEM allows power to flow bi-directionally and cooperatively when a high and a variable number of renewable sources is integrated, to ensure the system stability, flexibility, reliability and service continuity. The DEM interact in real time with demand and production from distributed generators and RES such us wind solar hydro... etc, following the system requirements thanks to a smart energy management system [1]

The MAS uses a highly distributed topology which matches exactly with the new network architecture [2]. Intensified and sustained research brings more interest to realize a complex and an advanced energy network, supporting intermittent and generators variable output [3]. The DEM by MAS can deal with the system instability when a high number of RES is implemented, causing, therefore power fluctuation [4] [5]. The MAS autonomy can be the key profile of the future smart energy network allowing the 'system-thinking' and 'system decisionmaking', to perform the required action and therefore increasing system flexibility. Furthermore, MAS had shown the sign of success in term of restoration issues by tolerating faults and outages when occurring [6] [7] [8].

Nowadays a custom role for power electronics is the development of energy from renewable sources and meeting challenges of the new architecture network, by extracting

- E-mail address: soukainabdh@gmail.com

ISSN: $1791-2377$ C 2017 Eastern Macedonia and Thrace Institute of Technology. All rights reserved. the maximum power from the sources and conditioning powers between all elements [9] [10]. Thereby advanced control algorithms are needed and real model of each element is required, to take full advantages from all devices interconnected. MAS is a multi-threaded program which each agent represents its own program in a form of behavior. Discontinuous nature of the control algorithm by MAS and its sampled feature makes the power electronics command and the electrical modeling issue of each element quite complex. This paper comes to propose a user-friendly method to model and control dynamic system with continuous states by MAS, to bring more facilities in term of modeling MAS especially for non-developers designers.

FCs are green energy converters systems, produces zero emission. They are generally below MW [11], thus are adapted with RES, which makes the grid more distributed and renewable. FC and Electrolyser junction is a backup power system, the first one converts the hydrogen energy stored into electrical energy to be redistributed at a time of scarcity. This energy from renewable sources, at a time of excess, is harvested by the second one to produce hydrogen. That can increase the use of RES [12].

The transition between the energy fossil fuels to ecological and environmentally friendly energy, and according to [13], where it is pointed out that the future hydrogen in the long term will be mainly obtained from RES, the development of a distributed energy network is necessary and increases the need to advance the $\mathrm{FC} /$ Electrolyser system. That why this paper proposes a 
distributed control for a PV-FC-Electrolyser system using MAS.

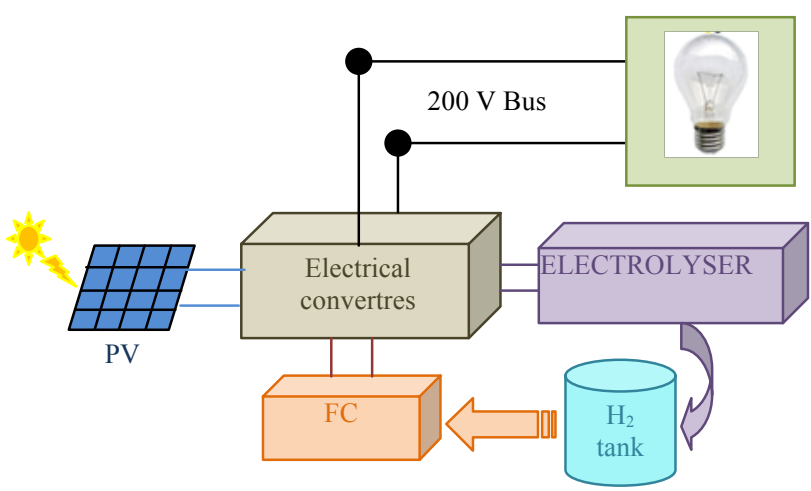

Fig. 1 PV-FC-Electrolyser system electrical layout

Section 2 presents the system studied. Section 3 describes the system modeling. The system control by MAS is justified in section 4 . The reliability of the proposed architecture is shown and discussed in section 5. Section 6 concludes the paper.

\section{System Presentation}

The load demand is not usually correlated with the RES generation that causes instability. Therefore the energy storage is required to avoid the RES fluctuations and to increase their high penetration [14] [15]. Unless the FCs are limited by their lifetime, the hydrogen can be stored for a very long time. The hydrogen production was studied in several articles as [16] and [17]. FC/ Electrolyser system coupled with RES as presented in Fig.1 stores the intermittent sources in the form of hydrogen to be used later. The hydrogen storage gives more reliability and effective cost than others storage means ( i.e battery) [18]. Selecting the best technology for energy storage is a technicaleconomic issue. In the configuration studied in this paper and following the characteristics of renewable resources and load profiles the system sizing is given as follow [19].

Table 1 Components' Sizes

\begin{tabular}{c|c}
\hline Element & Size \\
\hline$P V$ & $20 \mathrm{~kW}$ \\
$F C$ & $5 \mathrm{~kW}$ \\
Electrolyser & $20 \mathrm{~kW}$ \\
Load & $5 \mathrm{~kW}$ \\
\hline
\end{tabular}

The parameters of each element are summarized in Table 1. The FC acts as an auxiliary source, it supplies the load maximum power. It may occur that maximum load and zero generated power happened simultaneously. The Electrolyser maximum power is equal to the $\mathrm{PV}$ maximum generation power.

All these elements are linked to a DC bus as shown in the electrical layout of the system, described in Fig. 1. The FC supplies the missing power when the PV generation power does not suffice the load demand, by converting the hydrogen energy stored by Electrolyser while it occurs an excess electrical energy through the DC bus.

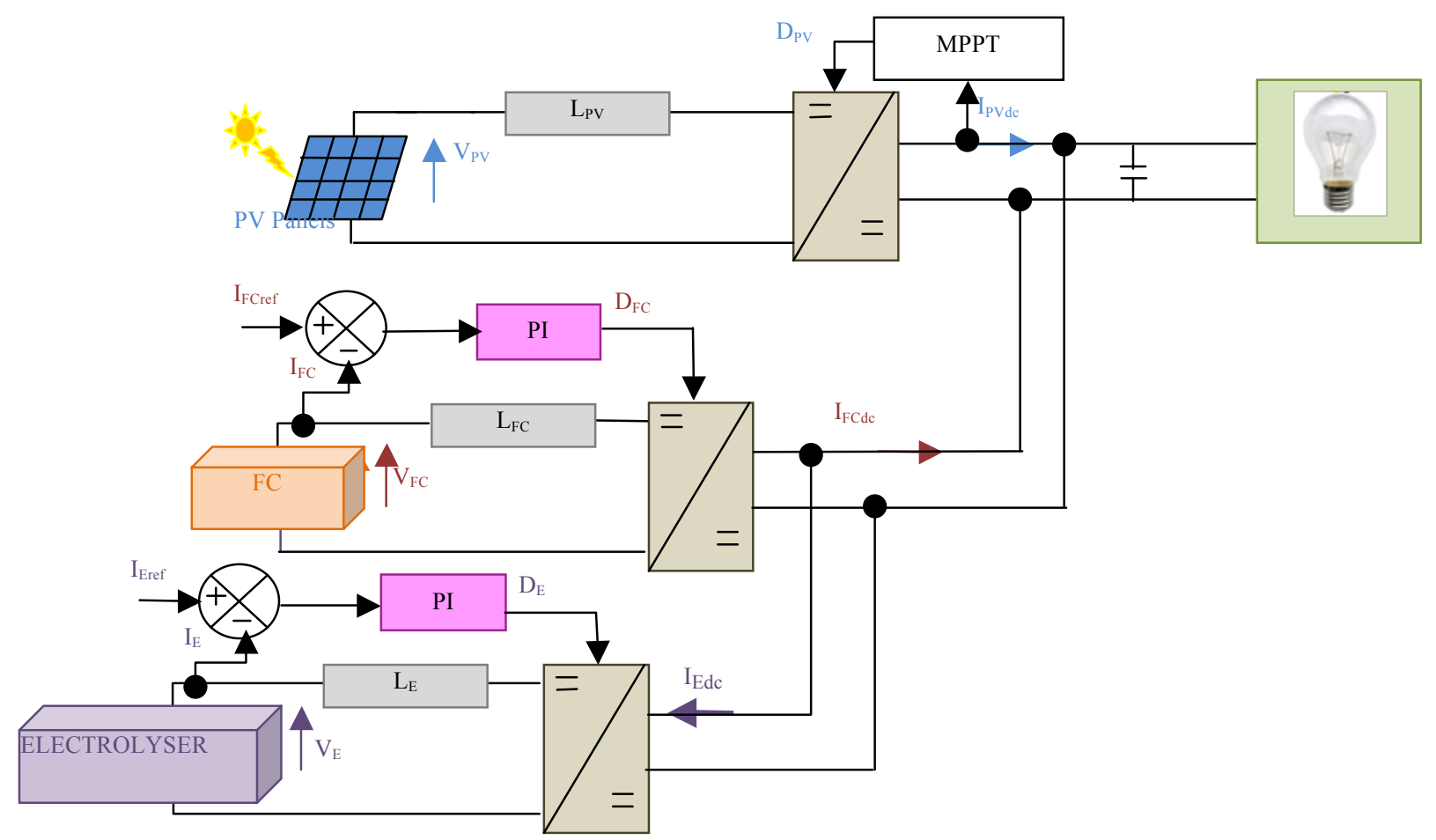

Fig. 2.PV-FC-Electrolyser system control principle

The difference between the generated and consumed power is inherently variable, it is sometimes positive or negative, depending if there is an excess or lack of power in the DC bus respectively. To meet this challenge, a scheduled control of the DC bus is required. Other challenges are added simultaneously, as ensuring the service availability and system stability, and meeting the load demand continually. Fig. 2 describes the suggested control. The PV panel is connected to the boost converter as expressed in (1), in order to boost the PV output voltage to the DC bus 
voltage, thanks to the Maximum Power Point Tracking (MPPT) that let the PV operates at the voltage corresponding to the maximum power extracted [20]. Boost and buck converters are connected to the FC and Electrolyser respectively for power conditioning as expressed in (2) and (3). Corresponding duty cycles $\mathrm{D}_{\mathrm{FC}}, \mathrm{D}_{\mathrm{E}}, \mathrm{D}_{\mathrm{PV}}$ are generated according to the strategy of energy management designed. Following PI correctors, the DC bus current is corrected, and assigned to the FC and Electrolyser converters input currents $\mathrm{I}_{\mathrm{FCref}}$ and $\mathrm{I}_{\mathrm{Eref}}$ respectively following the strategy of energy management, in order to generate the FC and Electrolyser converters output current $\mathrm{I}_{\mathrm{FCdc}}$ and $\mathrm{I}_{\mathrm{Edc}}$ respectively, while the main objective is to maintain the DC bus voltage constant as expressed in (4).

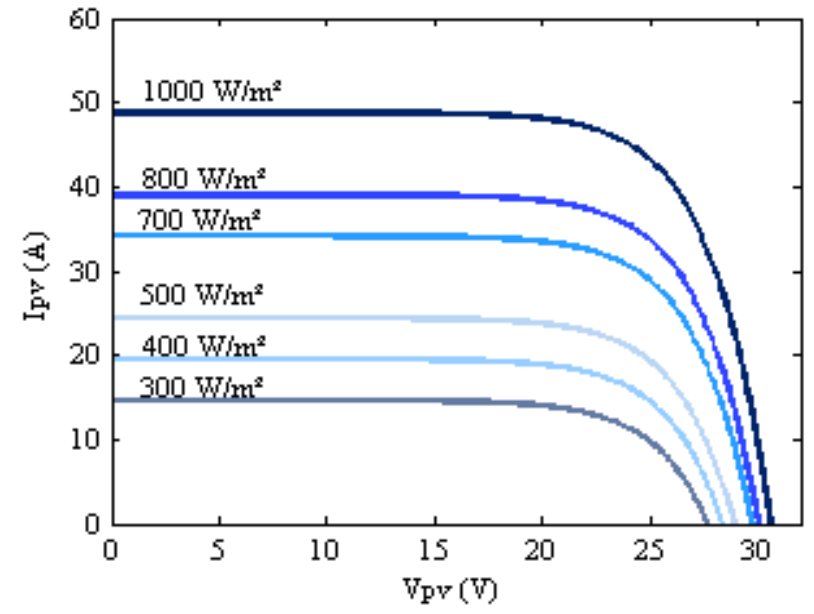

Fig. 3.I-V characteristic curves of the PV modules at different irradiances.

$$
\begin{aligned}
& L_{P V} \frac{d i_{P V}}{d t}=v_{P V}-\left(1-D_{P V}\right) v_{d c} \\
& L_{F C} \frac{d i_{F C}}{d t}=v_{F C}-\left(1-D_{F C}\right) v_{d c} \\
& L_{E} \frac{d i_{E}}{d t}=v_{E}-\left(1-D_{E}\right) v_{d c} \\
& C_{d c} \frac{d v_{d c}}{d t}=i_{P V d c}+i_{E d c}+i_{F C d c}+i_{L d c}
\end{aligned}
$$

The real model of the system components gives more reliability to the system control. Thus the model of each element is required. The PV, FC, and Electrolyser models have been developed using Matlab/Simulink. More details are given hereafter.

\section{Simulation Model}

\subsection{PV Model}

Fig. 3 shows the relations ship between the PV output voltage and the PV current under different irradiances at 25 ${ }^{\circ} \mathrm{C}$. The PV cell model is obtained following the currentvoltage $(I-V)$ characteristic as pointed out in [21] [22].

\subsection{FC and Electrolyser Model}

The FC and Electrolyser models are expressed in (5) and (6) respectively. However, the hydrogen storage function is given by calculating the hydrogen production and hydrogen consumption rate $\mathrm{V}_{\mathrm{E}}$ and $\mathrm{V}_{\mathrm{FC}}$ respectively as shown in (7).

$$
\begin{aligned}
& V_{e l}(T)=E_{0}(T)+R(T) * I+b(T) * \ln (I)+m(T) \\
& * \exp (I * n) \\
& V_{F C}(T)=E_{0}(T)-R(T) * I-b(T) * \ln (I)-m(T) \\
& * \exp (I * n) \\
& E_{H_{2}}=\int \frac{\Delta H}{V_{T}}\left(V_{e l}^{\bullet}(t)-V_{F C}^{\bullet}(t)\right)+E_{H_{2}(0)}
\end{aligned}
$$

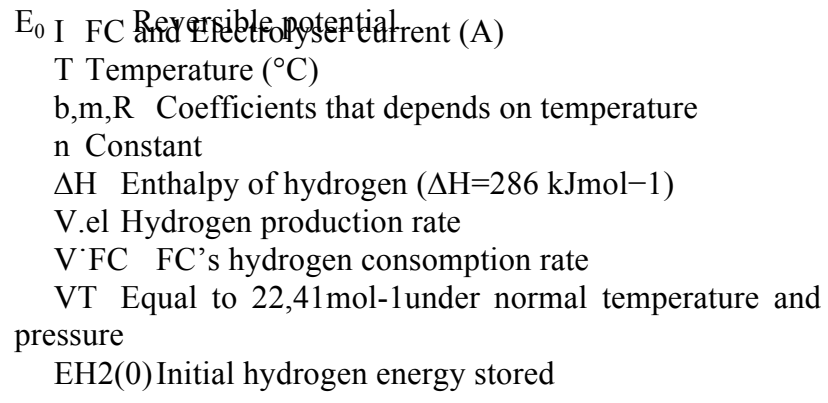

The power electronic plays a very important role in the distributed control. The PV-FC-Electrolyser system and corresponding converters models are based on the mathematical calculation that depends on continuous functions (integrals, differential equations, etc...). Distributed control by MAS of such a systems is quite complex. This is due to the sampled, discrete and discontinuous feature of MAS algorithms. A new architecture that allows expressing the distributed control of dynamic systems with continuous states is strongly required. In the following section authors propose a new approach, which is a user-friendly method destined for no computer developers users of MAS technique, allowing the distributed control of the PV-FC-Electrolyser system by MAS, in such a way, all the calculation required are made by Matlab/Simulink and the strategy of energy management is done by MAS, including agents negotiations and decisionmaking.

The MAS had shown the ability to perform an intelligent control system for complex systems. There are many methods available enabling agent modeling, but the software development method is widely applied. Thanks to Jade platform (Java Agent DEvelopment Framework) [26], MAS approach has been applied to a wide variety of areas, such as society, traffic control, robotics [27], energy [28], and electrical networks [29].

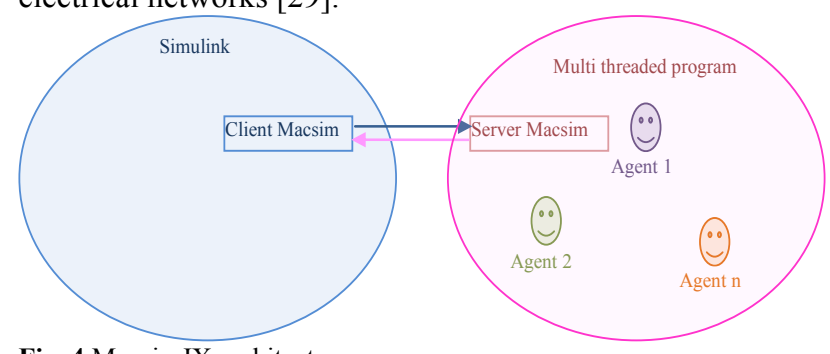

Fig. 4 MacsimJX architecture

MAS is a multi-threaded program, which each agent has its own and main program or thread as behavior. It transmits 
information between programs which are agent programs in the form of messages. In the other side, S-functions of Simulink is a very useful way enabling embedding programs written in other languages like for example $\mathrm{C}++$ or Java into Simulink. The communication between agents developed under Jade and S-functions causes instability, because of multi-threads of execution inside S-functions. MacsimJX is a multi-threaded program allowing liaising between a multithreaded environment like for example MAS and Sfunctions of Simulink, thanks to a separate program with protocols in place to ensure synchronicity [30]. It is very important to enable simulation and modeling of real-time distributed systems.

MacsimJX is characterized by client-server architecture, separating MAS from Simulink as shown in Fig.4. The server code is incorporated in separate programs [31], while the client part is integrated into Simulink through an Sfunction. Each agent has an apart program and receives data from Simulink, that lets MacsimJX possessing a parallel processing capacity.

Distributed systems modeling was firstly demonstrated by [32]. A flight control system was given to exemplify. Kalman filtering algorithm [33] was embedded into agents' algorithms, in order to control the flight vehicle. It was pointed out that agents receive the sensors' measurements coming from Simulink and generate continually the states measured according to Kalman algorithm. Then the vehicle is optimally controlled. If Thoroughness is asked, in this work, agents take over the flight control exclusively; however, Simulink deals with collecting data and displaying results. The following studies regarding the distributed control by MAS using MacsimJX [34] [35], have kept the same approach. That means agents take over the whole control and Simulink sends data and receives results for displaying. But there are other systems that evolving within an environment in a real-time, following continuous functions as described in the precedent section (PV-FCElectrolyser control system equation) that requires a scheduled control. Because of their discontinuous algorithms, agents developed under Jade are unable to easily control these dynamic systems. Besides, if the results given following the agents decision-making requires to be implemented in a real model to generate distributed control (like, for example, to assign the corrected current by PI corrector, to the converter input current in order to balance the DC bus); in these cases, the approach used in the previous papers cannot be applied. Also, we cannot take full advantages of the real model of system components, due to the discontinuous nature of the control algorithm. Therefore the distributed control of a dynamic system such as PV-FCElectrolyser by MAS using MacsimJX should be verified. Other studies regarding energy management using MAS are reported in [36] [37], In these papers the energy management was given, but agent language is considered as oriented object language, emphasizing that it is similarity between the both approach, but in fact there is quite difference between object and agent [38]. This paper gives significant contribution by the proposal of a new architecture allowing intelligent distributed control of complex systems such as PV-FC-Electrolyser to be easily used and in many other fields, regarding studies oriented towards artificial life. For these reasons, this paper shows how to liaise between Simulink and Jade, in such away, allowing agents collaborate together to achieve energy management objectives thanks to agents decision-making following data coming from Simulink because the system reaction and the agent environment update occur in Simulink.

\section{System Agentification}

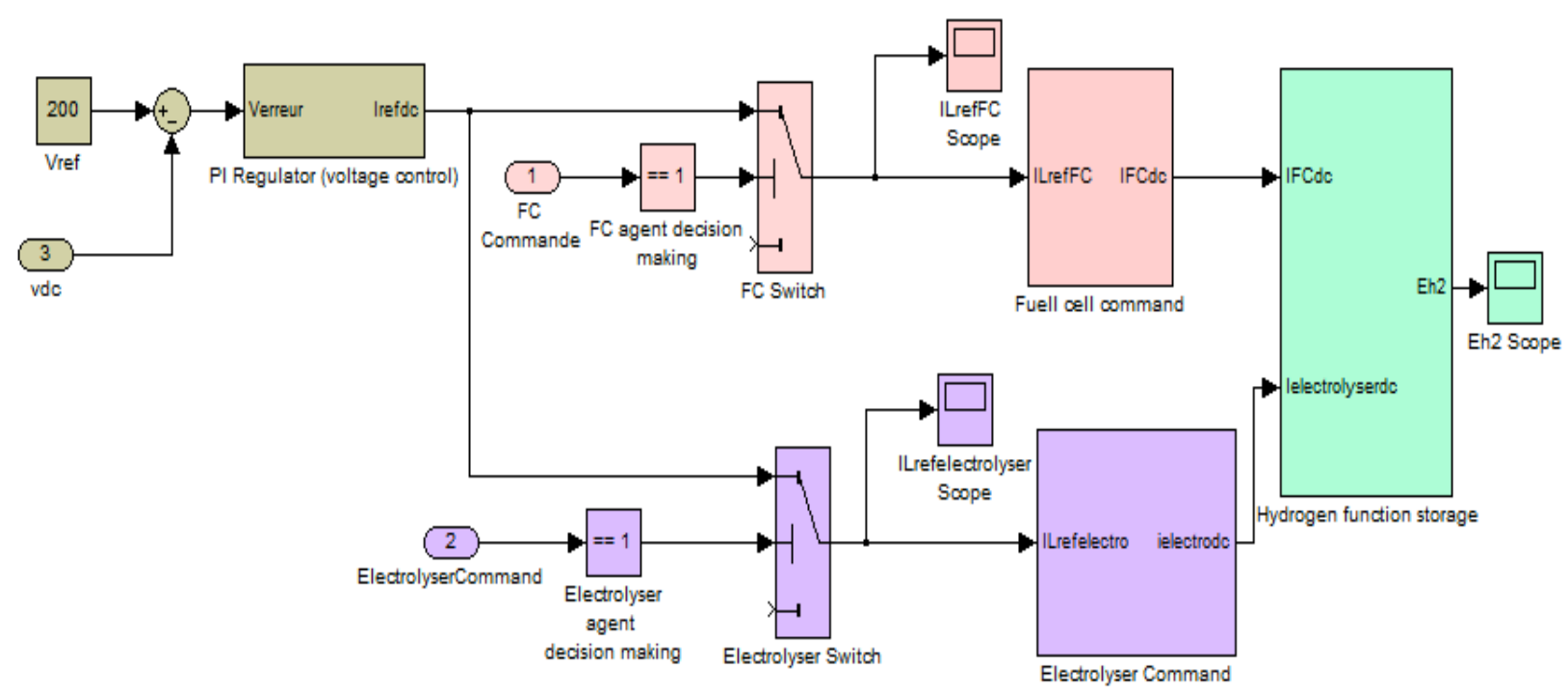

Fig 5. Simulink configuration of PV-FC-Electrolyser system control by MAS

Three agents are considered; coordinator agent, FC agent and Electrolyser agent. After extracting the PV maximum power, the PV current resulting is subtracted from the consumed current by the load. The currents difference is communicated to coordinator agent. In it side, it determines if there is a need to consume the extra power or the lack of power to be provided depending on the current difference sign. If a deficit of power is detected, it starts to propose to the FC agent to compensate the missing current. The FC agent decision-making depends on the hydrogen storage function, it refuses the coordinator agent proposal if the tank is empty and accepts it otherwise. In the other side, when an excess of power is detected by the coordinator agent, the 
Electrolyser agent receives the proposal. It has a reversible behavior comparing to the FC agent. His decision-making depends also on the hydrogen storage function, but it refuses the coordinator agent proposal if the hydrogen tank has reached its maximum limit and accepts the proposal otherwise. The FC and the Electrolyser agents receive from Simulink, the information about the hydrogen storage value $\mathrm{E}_{\mathrm{H} 2}$ for processing. When $\mathrm{E}_{\mathrm{H} 2}$ is correlated with the coordinator agent proposal, the $\mathrm{FC}$, and the Electrolyser agents send their decision-making as ' 1 ' and ' 0 ' otherwise. Agents' decision-making is then implemented in Simulink switch block in order to attribute the DC bus corrected current to the corresponding converter input current to control the DC bus as shown in Fig. 5. $\mathrm{E}_{\mathrm{H} 2}$ is then updated by calculating the integral as expressed above thanks to Simulink, in order to be returned back to the FC and Electrolyser agents for processing with the new coordinator agent proposal.

Agents decision-making is completed by an action in Simulink to show the complete system reaction, contrarily to the flight control study, where agents receive data available already in Simulink and control the vehicle thanks

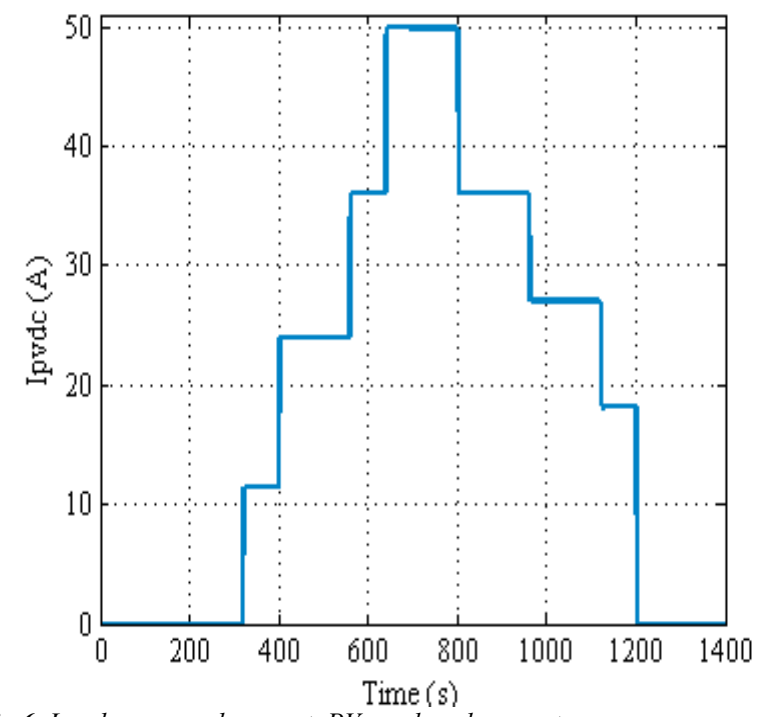

Fig.6. Load consumed current, PV produced current.

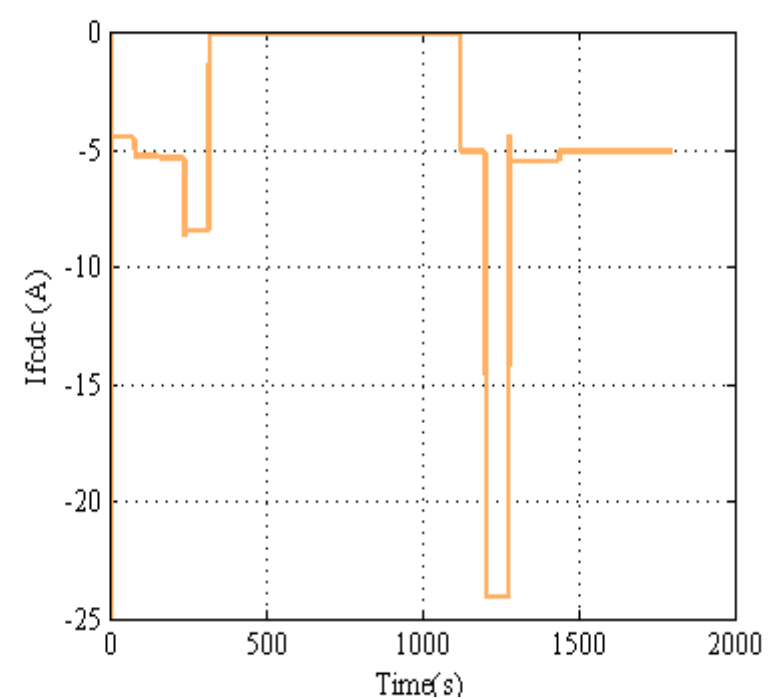

Fig. 7.FC converter output current, Electrolyser converter output current. to an incorporated algorithm and returns results for Simulink only for displaying. Here the FC and the Electrolyser agents processed data which is $\mathrm{E}_{\mathrm{H} 2}$ is continually renewed and depends on agents' environment reaction in a real-time. That means that the complexes mathematical calculations depending on continuous functions (like, for example, integral or differential equations) are required for agents' decision-making in order to perform distributed control by MAS.

\section{Results and Discussions}

In order to observe and to understand the system reaction with a changing configuration, three cases are separately treaty. In the first case, the storage control evolution is described. Then, the system reaction when FC and Electrolyser receive the proposal and their decision-making is studied in the second case, and in the third case, system stability and service continuity is shown.
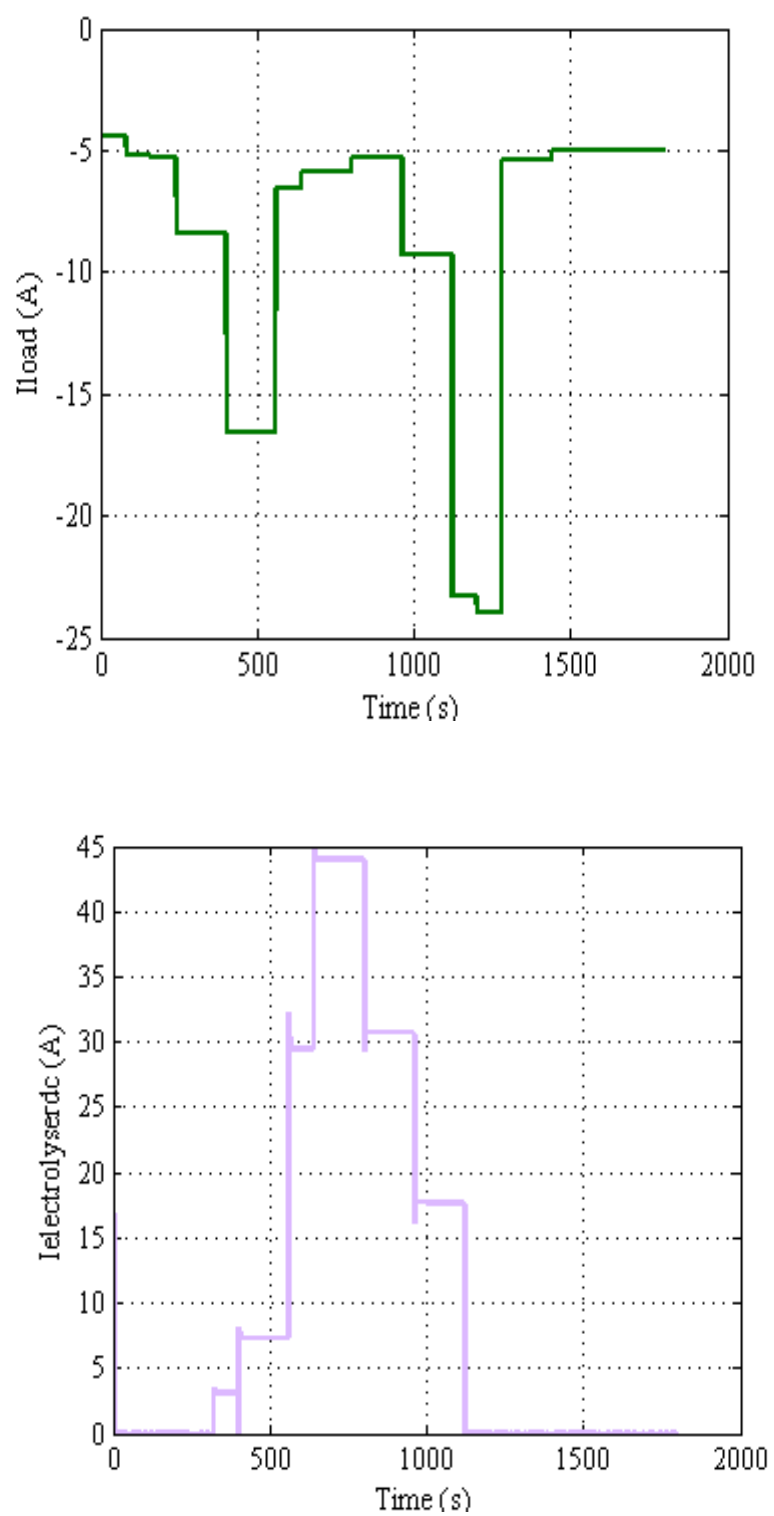


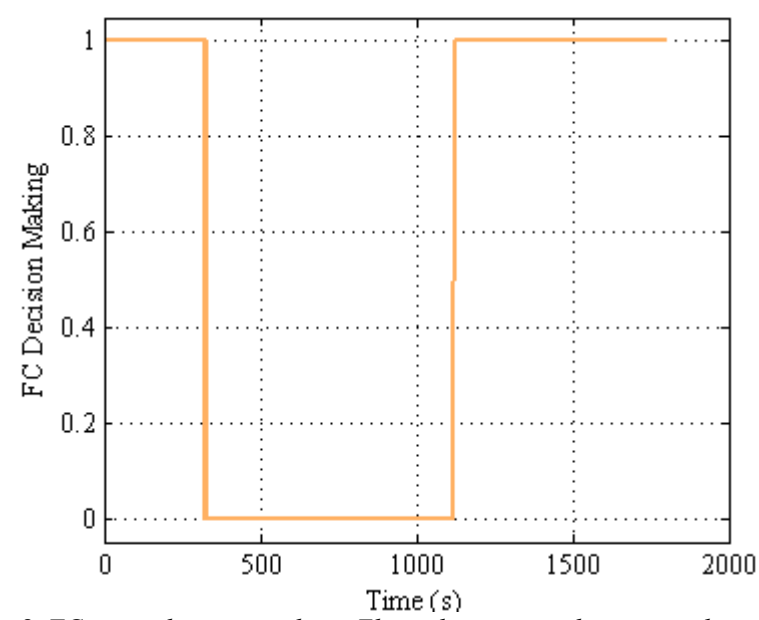

Fig.8. FC agent decision-making, Electrolyser agent decision-making.

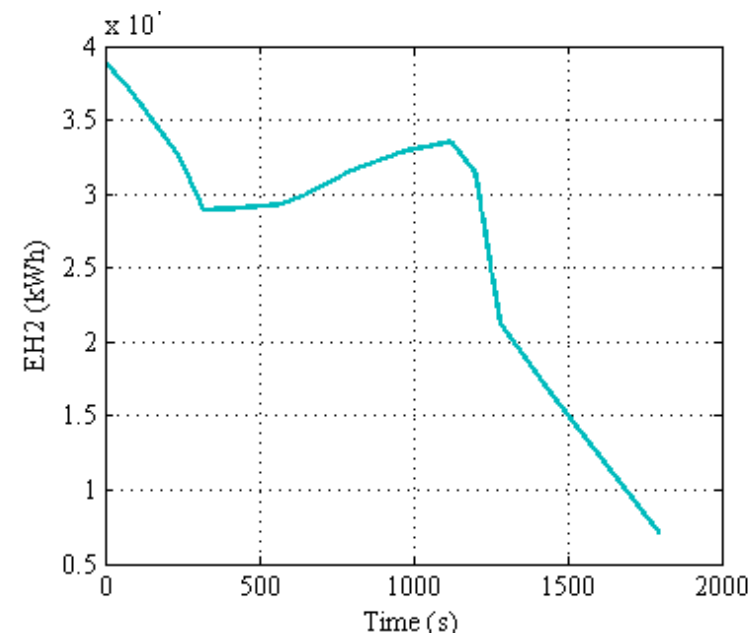

Fig.9. Hydrogen storage function evolution, DC bus voltage evolution.

\subsection{Storage Function Evolution Model}

Each agent receives from Simulink a data for processing. $\mathrm{E}_{\mathrm{H} 2}$ is the data processed by $\mathrm{FC}$ and Electrolyser agents. The consumed current shown in Fig. 6 subtracted from the PV current shown in Fig. 6 is the data processed by the coordinator agent. The stored hydrogen energy is the data processed by $\mathrm{FC}$ and Electrolyser agents. It was initially set at $3.8 \mathrm{kWh}$. The $\mathrm{E}_{\mathrm{H} 2}$ evolution is correlated with the $\mathrm{FC}$ converter output current $\mathrm{I}_{\mathrm{fcdc}}$ and Electrolyser converter output current $\mathrm{I}_{\text {electrolyserdc, }}$ as shown in Fig. 7 and Fig. 9. It increases when the Electrolyser in operation producing hydrogen while consuming the excess energy, and it decreases when the $\mathrm{FC}$ consumes hydrogen in order to provide the missing current through the DC bus. Once the coordinator agent, FC agent and Electrolyser agent are finishing from their processed data, the agents' decisionmaking are sent from agents to element modeled under Simulink, in order to distribute the DC bus control between the $\mathrm{FC}$ and the Electrolyser, depending on the case detected by the coordinator agent.

\subsection{Agents Decision Making and Distributed Control}

When the hydrogen tank allows consuming hydrogen by the FC, in order to convert it into an amount of electrical energy correlated with the energy should be supplied to the DC bus. As described above in Fig. 5, the FC agent sends its agreement expressed as ' 1 ' to the FC switch block enabling to affect the corrected DC bus current value to the FC converter input current, in order to generate the Ifcdc
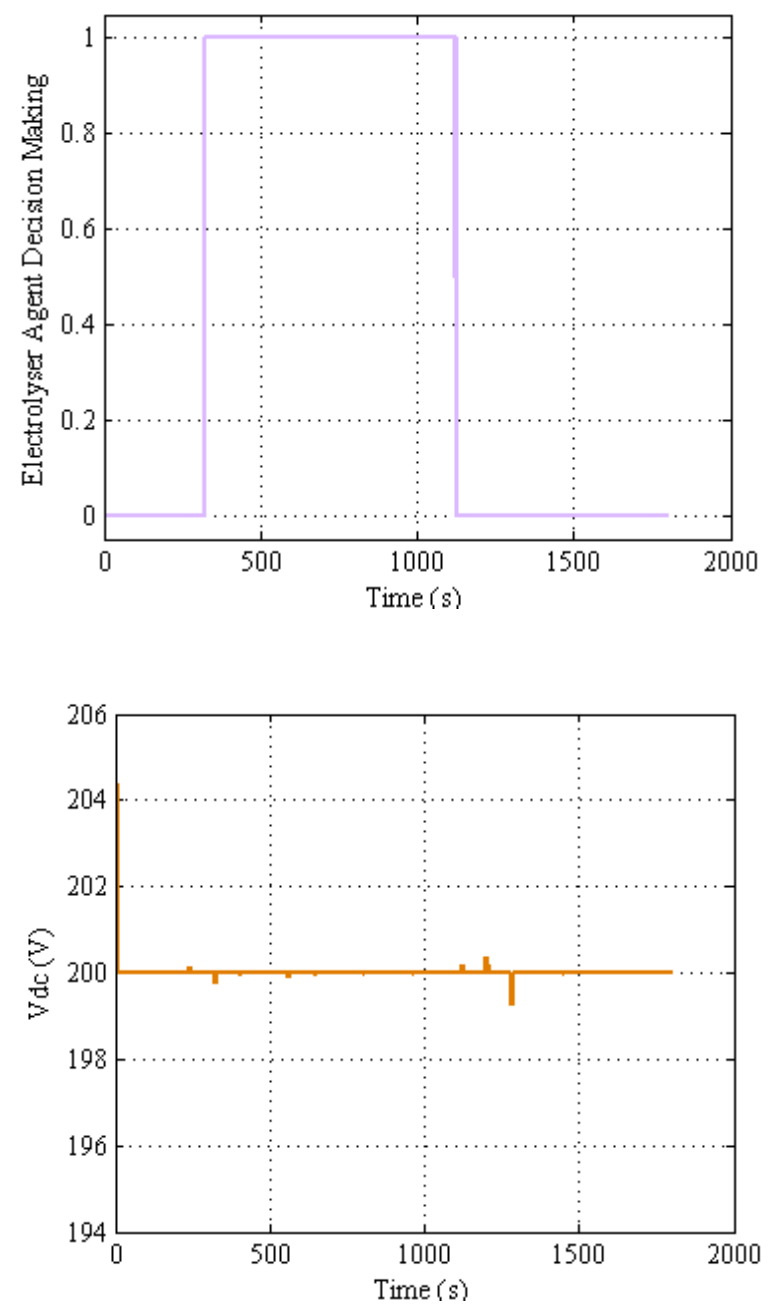

allowing the control of the DC bus by removing the lack of energy, and the $\mathrm{E}_{\mathrm{H} 2}$ decreases simultaneously. As shown in Fig.8, the FC agent decision-making always displays ' 1 'while the coordinator agent asks to supply energy, until that the $\mathrm{E}_{\mathrm{H} 2}$ reaches the minimum limits or the $\mathrm{FC}$ agent is not concerned by the coordinator agent proposal, to toggle FC agent decision-making to ' 0 '.

The DC bus control is distributed between FC agent and Electrolyser agent. When the FC agent is not concerned by the coordinator agent proposal, the proposal is addressed to the Electrolyser agent. In it side, sends its agreement expressed as ' 1 ' to the Electrolyser switch block when $\mathrm{E}_{\mathrm{H} 2}$ is correlated with coordinator agent proposal, that means the hydrogen tank is not full and can consume more electrical energy, in order to be stored in the form of hydrogen energy. Then the corrected DC bus current is assigned to the Electrolyser converter input current, to consume the excess of energy by injecting Ielectrodc in the DC bus and increasing $\mathrm{E}_{\mathrm{H} 2}$. The Electrolyser agent decision-making activates ' 0 ' when the hydrogen tank is full, or when it is not concerned by the coordinator agent proposal as shown in Fig. 8.

\subsection{Service Continuity and system Stability}

The PV-FC-Electrolyser system is alternatively and continually controlled. Fig. 9 expresses the DC bus voltage evolution during simulation time. It is shown that it is kept constant equal to the DC bus voltage reference, even if the system has undergone multiple variations caused by the intermittent PV generation and the sudden load consumption changes. 


\section{Conclusion}

S-function of Simulink has shown the ability to communicate with programs created in $\mathrm{C}++$, Java ...etc, which are unthreads programs. However while it is required to liaise between a multi-threaded environment like for example MAS created under Jade and S-function, instability is caused in Simulink. MacsimJX comes to solve the instability issue, allowing simulation and modeling of realtime distributed systems. Available studies regarding distributed control by MAS cannot be generally applied in many fields as compared and justified above. PV-FCElectrolyser system is a green hybrid system that needs a scheduled control due to the intermittent nature of the PV generation. Thereby the call of the concept of the intelligent energy management system is really required. A distributed control by MAS was given in this paper, where it was shown the capacity of the architecture proposed to attribute the decision-making to agents and performing all the calculation required by Simulink to take full advantage of the representation of real models of elements and gives more reliability to the system control. Finally, the results analysis had shown the strengths of the proposed architecture, in order to control dynamic systems with continuous states such as PV-FC-Electrolyser system.

This is an Open Access article distributed under the terms of the Creative Commons Attribution Licence

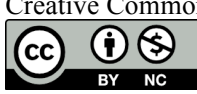

\section{References}

1. Sauter T, Lobashov M. 'End-to-end communication architecture for smart grids.’ IEEE Trans Indus Electron 2011.

2. F. Katiraei, R. Iravani, N. Hatziargyriou, and A. Dimeas, 'Microgrids management,' IEEE Power Energy Mag., vol. 6, pp. 54-65, 2008.

3. Wan Y-H, Parsons BK. 'Factors relevant to utility integration of intermittent renewable technologies'. National Renewable Energy Laboratory; August 1993.

4. J. Zeng, J. Wu, J.-F. Liu, L.-M. Gao, and M. Li, “An agent-based approach to renewable energy management in eco-building," in Proc.IEEE Int. Conf. Sustainable Energy Technologies, 2008 (ICSET 2008),2008, pp. 46-50.

5. D. E. Olivares, C. A. Canizares, and M. A. Kazerani, "Acentralized optimal energy management system for microgrids," in Proc. IEEE Power Energy Soc.Gen. Meet., Jul. 2011, pp. 1-6.

6. A. Prostejovsky, W. Lepuschitz, T. Strasser, and M. Merdan, "Autonomous service-restoration in smart distribution grids using Multi-Agent Systems,"25th IEEE Canadian Conference on Electrical and Computer Engineering (CCECE), 2012.

7. Khamphanchai, W.;Pipattanasomporn, M., and Rahman, S., "A Multi-Agent System for Restoration of an Electric Power Distribution Network with Local Generation," IEEE Power and Energy Society General Meeting, 2012.

8. W. Khamphanchai, M. Kuzlu and M. Pipattanasomporn, "A Smart Distribution Transformer Management with Multi Agent Technologies," IEEE PES Innovative Smart Grid Technologies, 2013

9. Liserre TS M, Hung JY.' Future energy systems e integrating renewable energy sources into the smart power grid through industrial electronics'. IEEE Ind Electron Magazine March 2010.

10. Carrasco JM, Franquelo LG, Bialasiewicz JT, Galvan E, Guisado RCP, Prats MM, et al. 'Power electronic systems for the grid integration of renewable energy sources: a survey'. IEEE Trans Ind Electron 2006;53:1002e16.

11. X. Zhang, and al, 'Towards a smart energy network: The roles of fuel/electrolysis cells and technological perspectives' journal of hydrogen energy $40\left(\begin{array}{lllll}2 & 0 & 1 & 5\end{array}\right) 6866 \mathrm{e} 6919$.

12. Weisser D, Garcia RS. 'Instantaneous wind energy penetration in isolated electricity grids: concepts and review’. Renew Energy 2005;30:1299e308.

13. Lymberopoulos N. 'Hydrogen production from renewables'. Project Technical Assistant Framework Contract, NNE5- PTA2002-003/1. September 2005.

14. Bueno C, Carta JA. Wind powered pumped hydro storagesystems, a means of increasing the penetration ofrenewable energy in the Canary Islands. Renew SustainEnergy Rev 2006.

15. Zhang X, Tan S-C, Li G, Li J, Feng Z. 'Components sizing of hybrid energy systems via the optimization of power dispatch simulations'. Energy 2013.

16. Barbir F. 'PEM electrolysis for production of hydrogen from renewable energy sources'. Sol Energy 2005.

17. Ulleberg O. 'The important of control strategies in PVhydrogen systems'. Sol Energy 2004.

18. ElectraGenTM telecom backup power solution delivers compelling benefits in Telstra network Ballard Market Update; 19 November 2013
19. D. B. Nelson, M. H. Nehrir, and C. Wang, "Unit sizing and cost analysis of stand-alone hybrid Wind/PV/fuel cell systems," Renewable Energy, vol. 31, no.10, pp. 1641-1656, Aug. 2006.

20. Shridhar Sholapur, K. R. Mohan, T. R. Narsimhegowda," Boost Converter Topology for PV System with Perturb And Observe MPPT Algorithm," IOSR Journal of Electrical and Electronics Engineering (IOSR-JEEE), vol 9, pp 50-56, 2014.

21. N. Pandiarajan and Ranganath Muthu," Mathematical Modeling of Photovoltaic Module with Simulink," International Conference on Electrical Energy Systems (ICEES 2011), 3-5 Jan 2011.

22. J.A. Ramos Hernanz, J.J. Campayo, J. Larranaga, E. Zulueta, O. Barambones, J. Motrico, U. Fernandez Gamiz, I. Zamora, " Two photovoltaic cell simulation models in Matlab/Simulink,"Int $J$ on Technical and Physical Problems of Engineering (IJTPE), vol. 4, no. 1,pp. 45 51, March. 2012.

23. T.Zhou and B.François, "Real-Time Emulation of a Hydrogen ProductionProcess for Assessment of an Active Wind-Energy Conversion System," IEEETransactions on Industrial Electronics, vol. 56, no. 3, March 2009;

24. K.Agbossou,, M.Kolhe, J.Hamelin, T.K. Bose, "Performance of a Stand-Alone Renewable Energy System Based on Energy storage as a hydrogen", IEEE Transactions on Energy Conversion, vol. 19, no. 3, September 2004.

25. Kélouwani, K. Agbossou, and R. Chahine, "Model for energy conversionin renewable energy system with hydrogen storage," Journal of Power Sources,vol. 140, no. 2, pp. 392-399, Feb. 2005.

26. Fabio Bell feminine, Telecom Italy, "Giovanni Caire, telecom Italy”Developing Multi Agent Systems with JADE “John Wiley\& sons 2007".

27. Fabrice LAURI, Abderrafiaa KOUKAM."Robustness Analysis of Multi-Agent Patrolling Strategies using Reinforcement Learning." In Proc. Of International Conference on Swarm Intelligence Based Optimization, 2014.

28. M. Mao, P. Jin, N. D. Hatziargyriou, and L. Chang, " MutiagentBased Hybrid Energy Management System For Microgrids," IEEE Transactions on Sustainable Energy, vol 5, pp.938_946, Avril 2014.

29. R.Roche, "Algorithms and Architectures for Multi-Agent Energy Management in Smart Electrical Networks, " PhD Thesis, December 2012;

30. C. R. Robinson, "Decentralised data fusion using agents," Ph.D. dissertation, The University of York, 2008

31. [31] Mendham, P. \& Clarke, T. (2005b), 'On achieving true autonomy: Using multi-agent control for a space plane', in 'Eurospace Conference on Data Systems in Aerospace (DASIA 2005)', pp. 335 - 339, Edinburgh, Scotland, UK

32. Charles R. Robinson, Peter Mendham, and Tim Clarke, "MACSimJX: A Tool for Enabling Agent Modelling with Simulink using JADE," JOURNAL OF PHYSICAL AGENTS, VOL. 4, NO. 3, SEPTEMBER 2010.

33. Simon Haykin "KALMAN FILTERING AND NEURAL NETWORKS", Copyright 2001 John Wiley \& Sons, Inc. ISBNs: 0-471-36998-5 (Hardback); 0471-22154-6 (Electronic)

34. Foo Eddy, YS, H. B. Gooi and S. X. Chen, "Multi-Agent system for distributed management of Microgrids," IEEE Transactions on Power Systems, vol 30,pp. 24 34, Mai 2014.

35. W. Khamphanchai, M. Kuzlu and M. Pipattanasomporn, "A Smart Distribution Transformer Management with Multi Agent 
Technologies," IEEE PES Innovative Smart Grid Technologies, 2013

36. J. LAGORSE 'A Multiagent Fuzzy-Logic-Based Energy Management of Hybrid Systems' IEEE Transactions on Industry Applications, vol. 45, NO. 6, December 2009
37. J. LAGORSE 'A multi - agent system for energy management of distributed power sources' in Renewable Energy 35 (1) :174 182. January 2010.

38. J. Ferber, Multi-Agent Systems: An Introduction to Distributed Artificial Intelligence. Reading, MA: Addison-Wesley, 1999. 